\title{
Exploring Primary School Teachers' Intention to Use E-Learning Tools during the COVID-19 Pandemic
}

\author{
Marina Aivazidi * and Christos Michalakelis \\ Department of Informatics and Telematics, Harokopio University of Athens, 17671 Kallithea, Greece; \\ michalak@hua.gr \\ * Correspondence: maivazidi@hua.gr
}

Citation: Aivazidi, M.; Michalakelis, C. Exploring Primary School Teachers' Intention to Use E-Learning Tools during the COVID-19 Pandemic. Educ. Sci. 2021, 11, 695. https://doi.org/ 10.3390/educsci11110695

Academic Editors: Christos Troussas, Akrivi Krouska, Cleo Sgouropoulou and Alexandra I. Cristea

Received: 31 August 2021

Accepted: 27 October 2021

Published: 31 October 2021

Publisher's Note: MDPI stays neutral with regard to jurisdictional claims in published maps and institutional affiliations.

Copyright: (c) 2021 by the authors. Licensee MDPI, Basel, Switzerland. This article is an open access article distributed under the terms and conditions of the Creative Commons Attribution (CC BY) license (https:// creativecommons.org/licenses/by/ $4.0 /)$.

\begin{abstract}
It is commonly accepted that the COVID-19 pandemic has had a crucial effect on many aspects of people's lives. The limitations placed on human relations have also affected education. The mandatory implementation of e-learning and the use of the information and communication technology tools in the teaching process have been the most important changes at all educational levels. However, the teaching staff plays a key role in every educational change. In this study, we examined the intention of elementary school teachers to use an e-learning platform. Our findings are consistent with those of previous studies, which have found that teaching skills, teachers' beliefs, and the appropriate infrastructure are all critical factors for the successful implementation of information technology in the educational process.
\end{abstract}

Keywords: e-learning; teaching skills; information technology in education

\section{Introduction}

At the end of the second decade of the twenty-first century, the COVID-19 pandemic affected almost every country in the world. The effects of the COVID-19 crisis were felt economically, socially, and politically-as usually happens in the case of a global crisis. Limitations on face-to-face communication in many aspects of life constituted a significant side-effect of the virus infection threat. The introduction of information and communication technology (ICT) was necessary to mitigate the consequences of communication restrictions both at work and in educational environments [1].

This led to the rapid and mandatory implementation of distance learning teaching methods in the educational process. Nevertheless, the adoption of information technology did not mean that the education community was appropriately prepared for those radical changes at all educational levels. The sudden cessation of the teacher's physical presence in the classroom with little time for the relevant preparations (due to the fact that schools were obliged to immediately adopt government mandates) explains the shortcomings in the implementation of these online learning techniques. The teachers and students had to adjust to the reality of the smart learning environment, which replaced the physical classroom. By the term 'smart learning environment', we mean a technology-supported learning environment that supports individual learners' needs while providing appropriate adaptations [2].

However, we must clarify that the purpose of smart education is not only to satisfy online educational needs in the era of COVID-19. Furthermore, as Ilkyu and Chonggun, [3] claim, smart learning offers learners an efficient learning environment with personalized mobile content and easy adaption to the current educational model. Smart learning requires smart technology devices, which encompasses the use of technological equipment, but according to Ha and Lee [4], smart learning is broader than the use of smart devices for learning purposes alone. More specifically, they see smart learning as the process of optimizing learning outcomes with the use of smart technology. 
As a matter of fact, we can look at the COVID-19 period as an opportunity for the implementation of ICT and smart technologies in education as well as a challenge for the development and the adoption of relevant modern and effective teaching methods. In this context, we must mention the crucial role of teachers in the success of the transition from traditional teaching methods to those of smart learning [4,5]. Previous studies have examined factors that affect teachers' perceptions of ICT technology in education and smart learning $[4,6,7]$. These studies were based on responses to questionnaires on teachers beliefs and their intent to implement e-learning technologies, but they all predate the COVID-19 pandemic.

In this paper, we contribute to the literature by focusing on teachers' intention to use ICT and e-learning tools. We employed quantitative and qualitative empirical approaches to measure teachers' efforts to implement web tools into the educational process and evaluate the content of the uploaded teaching materials. More specifically, we used qualitative content analysis to examine the educational materials that were uploaded onto the websites, blogs, social media, and e-class platforms of kindergartens and elementary schools. Furthermore, we implemented descriptive analysis to measure the intensity of e-learning tool adoption among elementary school teachers. Moreover, we used inferential statistics to look for any significant differences in the utilization of ICT for distance-learning purposes between kindergarten and elementary school teachers.

In the next section, we discuss the relevant research literature. Then, we state our research questions and hypotheses before proceeding with the quantitative and qualitative analyses and discussing our findings. Finally, we conclude by comparing our findings with those of previous studies.

\section{Literature Review}

The main purpose of this paper is to investigate the reactions of teachers to the mandatory implementation of ICT and e-learning technology in elementary education due to the difficulties and risks of conducting face-to-face learning during the SARS-CoV-2 global pandemic. As Hinostroza et al. [8] observed, the crucial role of teachers in the implementation of innovation and the adoption of digital technologies has been indicated in many prior studies $[5,9]$. We should mention that while the use of smart technologies constitutes a new learning paradigm [3], the vast majority of teachers have been trained primarily in traditional learning methods (i.e., methods that do not encompass smart technology) [8]. Palfrey and Gasser [10] suggested that teachers could be characterized as digital immigrants (who became familiar with ICT as adults), while students are digital natives (since they were born in the era of the developed Internet). Some studies have found that teachers are skeptical about ICT pedagogical perspectives and believe that there are serious limitations in terms of the lack of social interaction between students when making extensive use of ICT [7]. Specifically, they mentioned the opinion of a teacher in mathematics who viewed ICT in education as a threat that may prevent the development of students' mathematical thinking.

On the other hand, Naresh [11] found that ICT could contribute to the improvement of critical thinking and literacy skills and could also help teachers to apply innovative educational methods to improve educational outcomes. As we have already stated, based on the literature, teachers have been viewed as the key to the success or failure of the implementation of digital technology in education. Nevertheless, we should not assume that teachers will use smart learning technologies in the future, especially after the end of their mandatory adoption period caused by COVID-19.

Prior studies have shown that skill acquisition and motivation may be necessary for teachers, in order to encourage them to adopt and support the transition from the old traditional learning paradigm to the e-learning paradigm. Furthermore, according to Penalvo et al. [2], the adoption of smart learning technologies would make teaching easier. Of course, as they point out, the ultimate goal should not be the reduction of teaching effort but the improvement of learning outcomes. A decrease in teaching effort could be a 
motive, but no efficient transition can be expected without skill acquisition on the part of teachers. These skills will help teachers to respond to the challenges described by Zarei and Mohammadi [12]. These challenges can be split into the following three categories: (a) job, (b) equipment, and (c) students. Additional workload and psychological stress are classified as job challenges; technical knowledge of the e-learning platforms is identified as an equipment challenge; and motive provision, the interaction between teachers and learners, and cheating prevention are taxonomized as student challenges.

McLoughlin and Northcote [13] stated that the recent relevant literature suggests that the necessary teaching skills for online learning should not be limited to technological skills, but they should be extended to include instructional and communicative skills. In the same manner, an earlier study indicated that teachers' training in these new technologies must not be focused solely on the technical skills but must also encompass didactic competencies, such as the efficient planning and management of activities [14]. Taking a more extensive approach, Albrahim [15] enumerated seven categories of skills that teachers need for online learning: (a) pedagogical, (b) content, (c) technological, (d) design, (e) management, (f) institutional, and $(\mathrm{g})$ social and communication. We observe that all of the aforementioned studies agree on the fact that technical training alone is not adequate to produce efficient e-learning outcomes. Managerial, organizational, content, and technological skills were included in Lee and Hirumi [16], who also introduced interaction and teamwork skills as categories.

The proposed skill requirements in the academic research are consistent with those of professional studies. The authors of [17] added to communication and technological skills, knowledge of the industry and expertise on the subject being taught. Teaching expertise, communication skills, and supportive personal skills were also considered necessary in professional studies. McLoughlin and Northcote [13] concluded that interactive elements are required for both on-campus and online teaching. Moreover, they found that a simple presentation without facilitated interaction is not enough for online learning.

To summarize, we observe that the transition from traditional on-site learning to e-learning is not straightforward, as special skills are required to facilitate online learning. Consequently, teachers need training — not only for the adoption of e-learning but also for its efficient implementation.

\section{Research Questions and Methodology}

It has been shown in previous studies that teachers constitute a critical factor in the efficient implementation and use of ICT and e-learning tools in the educational process. However, we believe that outcomes will be poor if teachers, as key players, are unfamiliar with the required technology and have not been convinced of the advantages of utilizing ICT tools in the teaching process. On the other hand, during the COVID-19 period, the implementation of e-learning became mandatory for school teachers. In this study, we investigated to what extent primary and kindergarten school teachers managed to efficiently implement e-learning tools in the obligatory distance learning process. More specifically, we focused on their intention to use tools such as e-classes and whether they developed or utilized any additional tools, such as websites, blogs, or social media.

To this end, we formulated the following two research questions:

1. Did schools and teachers adopt the e-class tool in order to provide pupils with required and additional teaching materials? To what extent did they use e-learning tools?

2. Was the content of these e-classes, along with that of websites, blogs, and social media, adequate for the improvement of learning outcomes?

In order to answer these questions, we adopted both quantitative and qualitative empirical techniques. Based on previous studies $[3,18]$ that linked skills with outcomes, we considered teachers' e-learning skills and outcomes in the context of their intention to adopt computer learning technologies in the educational process. According to the instructions of the Ministry of Education in Greece, teachers had to use the Webex platform 
for teaching and e-classes for uploading teaching materials. Because the Webex platform had been used by all teachers on a daily basis for teaching, we examined the use of the e-classes to evaluate the intention of teachers to upload necessary and additional teaching materials. Two indices were developed for this purpose. The first compared the number of schools that used the e-class platform with the total number of schools. The second calculated the proportion of uploads per teacher. The data for both indices came from the e-class platform and the Greek Ministry of Education.

Our second research question was also approached empirically with a qualitative method. We conducted a content analysis of e-class materials and of school websites, blogs, and social media accounts for a deeper analysis of the tools that were used by teachers and schools during the COVID-19 period. Web-based content has been analyzed in prior studies. Kim and Kuljis [19] provided a case study to explain the appropriate steps for the improved analysis of web-based content. Moreover, Bengtsson [20] emphasized the processes of decontextualization, recontextualization, categorization, and compilation as distinct stages of content analysis. Prior studies have also specified and explained conventional, directed, and summative approaches to content analysis [21].

Using the data published by the e-class platform, we found that 4175 elementary schools and 3166 nursery schools had been active on the platform. We considered schools with at least one published file on the e-class platform to be active. The schools were distributed throughout 58 geographical regions. Of these schools, approximately $43 \%$ were kindergartens and 57\% were elementary schools. These proportions were reflected in our selected sample. The total size of the sample was 200 schools. We selected our sample from the two available lists of primary and kindergarten schools active on the e-class platform (eclass.sch.gr, retrieved 10 August 2021; additionally see the web address of a specific region, e.g., https: / / eclass01.sch.gr/modules / auth/opencourses.php?fc=20000).

For the purposes of our study, we were also provided with the official list of the primary education schools in Greece from the Ministry of Education. We implemented the systematic sampling method to select our sample. The total population was classified alphabetically into two lists. Each one included the schools of the two levels of primary education (kindergarten and elementary schools). Looking into the total sample, we observed that all the geographical areas were represented for both kindergarten and elementary schools. Systematic sampling is a method of probability sampling with significant elements of randomness that has been considered a useful sampling procedure when the sampling frame is included in a list [22].

Coding the content of the e-class sites of the schools, we defined the variables that were used to answer our second research question. Specifically, our variables were as follows:

- $\quad$ Type of uploaded files with educational material;

- Accessibility;

- Number of uploaded files with educational material;

- $\quad$ Gender of the teachers who uploaded educational material;

- Type of material (conventional or additional);

- Teaching subject of the uploaded material.

Regarding the additional web resources, we investigated and identified the following variables:

- $\quad$ Relevance to courses;

- $\quad$ Oriented to increased information needs caused by COVID-19;

- Visitor (teachers, pupils, parents) friendliness.

We should mention that by the term "files with educational material" we mean any type of file (docs, excel, ppt, pdf, etc.) that contains core, additional, or explanatory teaching notes, digital versions of books, or links to websites with any type of educational material on them used for teaching purposes. 
In the next section, we present and discuss our findings from both the qualitative and quantitative analyses. The qualitative analysis was based on the selected sample. Regarding the quantitative approach, our sample contained all the elementary and kindergarten schools that had demonstrated any activity on the e-class platform. The total number of these schools was 4175 elementary schools and 3166, as we have already explained, which constituted approximately $71 \%$ of the total number of elementary schools in Greece. In order to explore whether the elementary school teachers were significantly more active than the kindergarten school teachers, we implemented the Mann-Whitney non-parametric test for mean differences. We selected a non-parametric test due to the fact that there was no evidence that the values of the tested variables in the population and the sample were normally distributed.

\section{Results and Discussion}

In this study, we explored the degree to which teachers and schools responded to the compulsory adoption of computer-based distance teaching during the COVID-19 era. As we have already stated, we focused on primary education. Primary education in Greece is administrated by the Ministry of Education and is distributed into 58 regional directories of primary education. Our analysis was based on the available data for individual directorates. The number of elementary schools in Greece from which at least one e-class was uploaded was 4171 , accounting for $91 \%$ of the total number of elementary schools in Greece. Regarding kindergarten schools, we counted 3166 that uploaded at least one document onto the e-class. Unfortunately, that number reflected only $55 \%$ of all kindergarten schools in Greece (Table 1 and Figure 1).

Table 1. Descriptive statistics for schools' web tools implementation.

\begin{tabular}{ccc}
\hline & \multicolumn{2}{c}{ Type of School } \\
& Elementary & Kindergarten \\
\hline E-class uploads per type of school & $91 \%$ & $55 \%$ \\
Schools with sites blogs, or social media & $77.5 \%$ & $44.1 \%$ \\
Schools with websites & $35 \%$ & $16.3 \%$ \\
Schools with blogs & $50 \%$ & $32.5 \%$ \\
Schools with social media presence & $21.5 \%$ & $20 \%$ \\
\hline
\end{tabular}

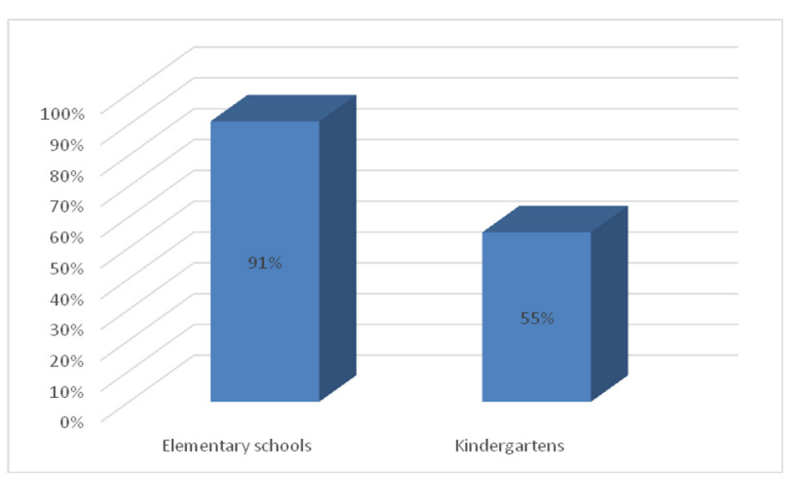

Figure 1. E-class uploads per type of school.

Looking at Table 2, we also observed that the kindergarten schools presented less activity than the elementary schools. The difference between the regional average of uploads per elementary school and those of the kindergarten schools was identified as statistically significant at a confidence level of less than $1 \%$ (Table 3). Although we believe that this finding should be examined further, we should mention that, in our qualitative approach, we observed that fewer than half of all elementary school teachers uploaded educational materials to an e-class. With this in mind, while the elementary schools appeared to be prolific uploaders, the number of teachers who actually utilized the e-class 
is low. On the other hand, in the majority of kindergarten schools, the number of teachers is low. Thus, if the one and only teacher in a kindergarten (which represents a substantial number of these types of schools) does not use the e-class, the school does not appear in the e-class uploaded list. However, as can be seen in Table 2 (and more analytically in Table 4), the elementary school teachers published significantly more teaching materials in the e-class than the kindergarten teachers (level of significance less than 1\%).

Table 2. Descriptive statistics.

\begin{tabular}{cccccccc}
\hline Variables & Mean & St. Dev. & Min & Q1 & Med. & Q3 & Max \\
\hline Elementary schools with e-class & 71.91 & 43.56 & 11 & 41 & 64.5 & 95 & 215 \\
Kindergarten schools with e-class & 54.59 & 41.09 & 6 & 25 & 42.5 & 72 & 190 \\
E-class uploads (elementary schools) & 2440 & 2084 & 154 & 973 & 1754 & 3065 & 9702 \\
E-class uploads (kindergartens) & 519 & 578.4 & 21 & 126.8 & 296.5 & 699.3 & 2464 \\
\% Tenure teachers (elementary schools) & 73 & 13 & 44.4 & 61.9 & 76 & 84.3 & 92.3 \\
\% Tenure teachers (kindergartens) & 67 & 16.2 & 31.9 & 54.5 & 67 & 81.4 & 26.8 \\
Uploads per teacher (elementary) & 2.87 & 0.921 & 0.726 & 2.217 & 2.84 & 3.58 & 5.091 \\
Uploads per teacher (kindergarten) & 1.873 & 1386 & 0.26 & 0.825 & 1.496 & 2.418 & 6.553 \\
\% Elementary schools with e-class & 91.7 & 9.1 & 41.9 & 89.7 & 92.54 & 97.4 & 100 \\
\% Kindergarten schools with e class & 55.3 & 14.1 & 11.2 & 46.6 & 55.2 & 64.8 & 84.2 \\
\hline
\end{tabular}

Table 3. Mann-Whitney test for the difference between the upload averages of elementary and kindergarten schools.

\begin{tabular}{cccc}
\hline Variables & Median & W Value & $p$ Value \\
\hline Uploads average (elementary schools) & 30.35 & 4835 & 0.000 \\
Uploads average (kindergarten schools) & 6.64 & & \\
\hline
\end{tabular}

Table 4. Mann-Whitney test for the difference between the average number of uploads per teacher in elementary and kindergarten schools.

\begin{tabular}{cccc}
\hline Variables & Median & W Value & $p$ Value \\
\hline Uploads average per teacher in elementary schools & 2.83 & 4302 & 0.000 \\
Uploads average per teacher in kindergarten schools & 1.49 & & \\
\hline
\end{tabular}

In addition to this finding, we observed that the average of the kindergarten schools was greater only in 8 of the 58 examined regional directorates. However, we should mention that, according to Tables 2 and 4, the number of uploads per teacher can be considered very low for both kindergarten and elementary schools. The fact that teachers published material on average two or three times per year and the maximum values were no higher than five or six times per year reflects the extremely low publishing rates-less than once per month even for the most prolific teachers. We believe that this finding should be examined further since it constitutes evidence of low intention to use the e-class on the part of the school teachers. We can also assume that there was a lack of motivation and skills, but we believe that interviews with the teachers are necessary to conclude this more confidently. In the second research question, we investigated whether the content of the e-class uploads could positively affect learning outcomes. As we have already noted, the mean and the median value of the uploads per teacher to the e-class platform were extremely low.

The relevant index we provided in the current survey concerned all school teachers. Nevertheless, we assumed that the fact that there were teachers with no publications in the e-class platform explains the observed low mean and media values for e-class uploads. Using systematic sampling, we selected a sample of 200 schools, in which at least one upload had been identified. The sample size was evaluated as adequate, since no significant findings were identified when increasing the sample size. Looking at our 
sample, we observed that the proportion of teaching staff who published at least one file with educational material was low in both the kindergarten and elementary schools in the sample. In other words, we detected that teachers had very little interest in publishing any educational material in the e-class.

We coded and explored more variables to evaluate the adequacy of the published educational material for the learners. We first noticed the lack of a teaching syllabus in the vast majority of the published documents. The evaluation of the teaching material content was not possible in many schools since the teachers did not allow free access to anyone except the users (pupils). Thus, we focused on the open access publications and the titles of the limited access ones. Our findings could be an indicator of the beliefs of the teachers regarding the diffusion of knowledge with the implementation of computer-based learning methods.

Courses such as language studies, mathematics, English language, and history appeared more frequently than physics, geography, information technology, and German and French languages in the elementary school. Links to websites, slides, quizzes, and learning games were the most common type of the educational material. Additionally, picture files (jpeg, jpg) were found in the e-class platform. Nonetheless, we detected a low number of documents and PowerPoint files. This observation could indicate that the teachers did not intend to develop educational material but preferred to upload material from websites on which such material was available. Moreover, the low publishing activity on the e-class platform of information technology teachers came as a big surprise to us since they were expected to be more familiar with and trained in the use of ICT and e-learning technologies than the teachers of other subjects that were less oriented to computer-based learning.

No significant difference in the gender of the publishers was detected. Regarding the content of the uploaded files, we identified fewer additional teaching materials, compared to conventional materials, that were focused on the daily teaching needs of the course. However, the quantity of the notes, quizzes, and other teaching material was not adequate to cover the total content of the relevant courses.

Similar findings were detected in the kindergarten schools. As was expected, the topics of these schools differed from those of the elementary schools. Specifically, seasons, the environment, physiology, and feelings were identified as the most frequently uploaded subjects for these younger pupils. Furthermore, we should mention the low interest that kindergarten teachers had in publishing any material. Although some of them were registered on the e-class platform, many never introduced a single e-learning course, and they appeared to be trial users. Based on this evidence, we can assume that they were either not appropriately trained on the use of these learning platforms or they were not interested in publishing any kind of educational material.

As a matter of fact, the e-class platform was not the only platform that was used by the teachers of primary education. By searching the Internet, we found blogs, web pages, and social media pages (especially Facebook) that had been developed by the schools to communicate with students and their parents or to provide them with necessary information. As can be seen in Table 1 and Figure 2, 77.5\% of the elementary schools and $44.1 \%$ of the kindergarten schools in our sample developed at least one web tool to communicate with their students and the wider community. The tools that were examined in this study were the schools' web pages, blogs, and their Facebook pages. The main differences between them and the e-class platforms were their target group and the type of information they provided. Specifically, the e-class was designed for educational purposes. On the other hand, even though the school web pages, blogs, and social media pages contained teaching material, they were primarily developed to provide information to the school's stakeholders, such as the pupils' parents and any social groups or individuals who were interested in the school. Furthermore, they also constituted communication tools, since everyone could communicate with the schools using social media, blogs, and the schools' websites. 


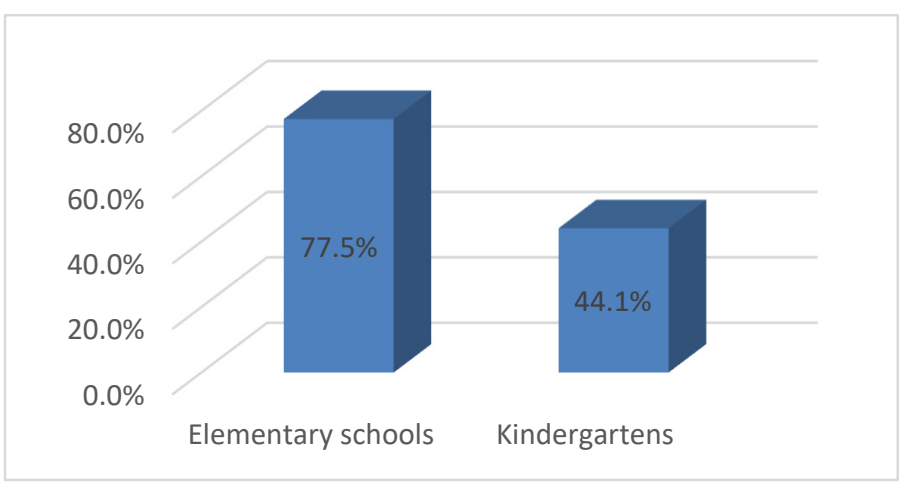

Figure 2. Schools with websites, blogs, or social media.

The information on a school's web page, blog, or social media page was not limited to teaching material, as these platforms could also be used instead of the class for teaching purposes if necessary. In this study, we also investigated whether the elementary school teachers used web tools to make their teaching material available to students.

As can be seen in Table 1 and Figures 3-5, blogs were the most commonly used web tool in elementary schools. Web pages were less often developed. When looking into the web pages of the included schools in our sample, we noticed that the schools' web pages were usually developed in the environment of the official Panhellenic School Network (http:/ / sch.gr, retrieved 10 August 2021) or they appeared (though not as often) as subweb pages in the Municipality Authority websites. They provided information on the schools' history, activities, teaching schedules, announcements for their future activities, decisions by the school board, instructions for COVID-19, and school participation in the Erasmus Program or other European funded programs for education and teaching innovation improvement. Blogs and websites included almost the same information. According to our observations, schools preferred to develop blogs to web pages. In addition, the blogs were kept more up to date than websites.

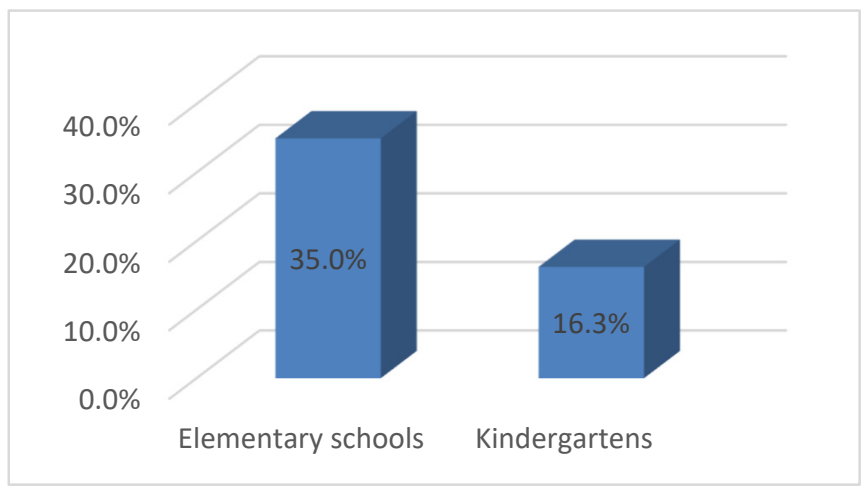

Figure 3. Schools with websites.

Blogs and websites also provided updates on coronavirus mitigation strategies and parents' unions, while they also included links to educational videos and games or links to online courses. On both blogs and web pages, many photos were found for education activities and links to e-classes. Unfortunately, we cannot claim that all uploads and their contents were adequate for the teaching needs of every individual course because the publication activity was so poor. We should note that the number of publications on these sites was smaller than those on the e-classes and that their contents were poorer. Moreover, the detected publications reflected fewer courses than those of the e-classes.

Regarding the schools' Facebook pages, we observed that they included summarized information and that they were used more for communication purposes. Recently, specifically during the coronavirus restrictions, they were used as additional information sources 
for relevant coronavirus announcements. Nevertheless, we should mention that while exploring Facebook, we detected many unofficial school pages. Thus, we believe that it is unwise to consider all information provided on this platform reliable.

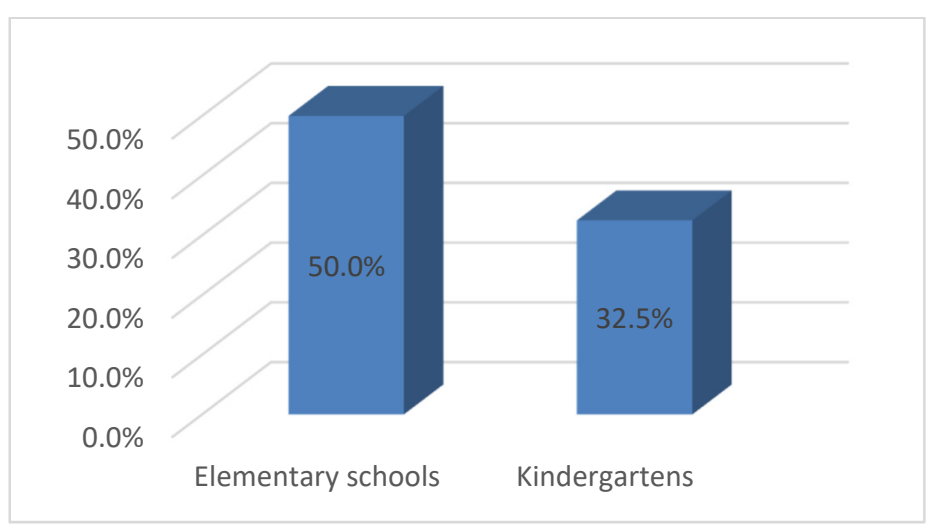

Figure 4. Schools with blogs.

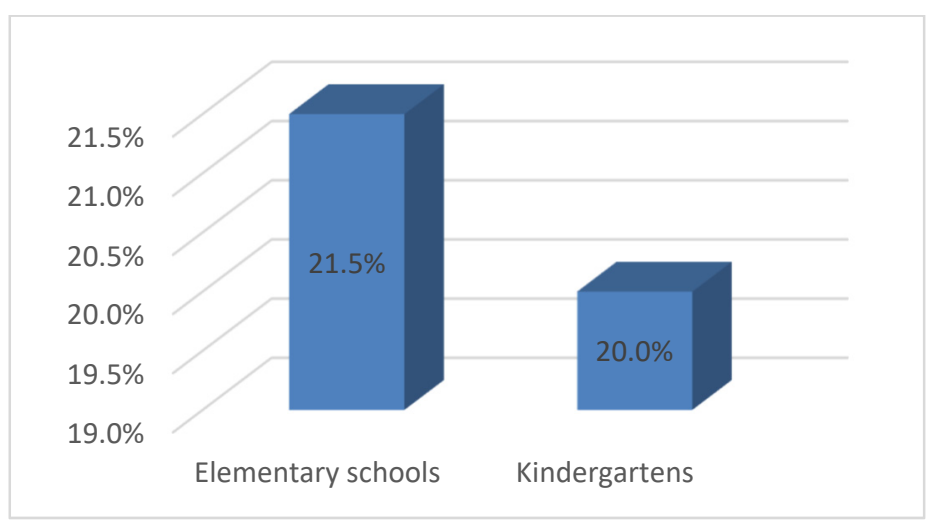

Figure 5. Schools with a social media presence.

To conclude this discussion on the analysis of our results, we should mention the low frequency with which files were uploaded onto the e-class platform. In addition, we observed that the teachers in both kindergarten and elementary schools avoided developing any explanatory or additional teaching materials for their students. Instead, they preferred to upload educational material they found on the web to their e-class. We also found evidence that the teachers in kindergarten schools showed significantly less interest in publishing and consequently developing educational material than their counterparts in elementary schools. Furthermore, we detected poor content in the published educational materials in terms of the number of uploaded files and the quality of their contents. Additionally, teachers did not exclusively use official web tools for e-learning, since they uploaded material or announcements onto non-official platforms (e.g., social media, blogs) but not on the e-class platform or the official school web page. The above findings contribute to the literature since they constitute evidence that the key players in the e-learning procedure did not seem to demonstrate any significant interest in the development of e-learning material and the use of the e-learning web tools, even in a period of mandatory distance learning based on ICT tools. Moreover, our findings indicate that a change in the legal framework - which made the implementation of e-learning methods and tools obligatory-was not adequate for the successful transition to the era of e-learning and smart education. The development of a relevant educational policy should be based on providing motivation, training, and skill acquisition and the fostering of a new culture oriented towards the adoption of ICT education. 


\section{Conclusions}

This study has been undertaken to study elementary school teachers' intention to make sufficient use of e-learning tools to meet the teaching needs and improve the teaching process in the period of the coronavirus crisis. During this period, the distance learning process became mandatory. Prior research has found that the transition from face-to-face teaching to distance learning requires teachers to have already acquired the appropriate teaching skills and the necessary technological equipment while maintaining a positive attitude towards the e-learning process [12-14,16,23]. Furthermore, the teaching beliefs for e-learning are related to the use of ICT technology [24] and, obviously, with the availability of the appropriate infrastructure and teaching skills.

Using descriptive quantitative analysis and the qualitative content analysis, we developed indicators to evaluate the use of the official e-learning platform by elementary school teachers, as well as the content of their publications while we also searched for alternative web sources on which teachers might have uploaded teaching materials. We found evidence that the teachers of elementary schools in Greece did not intend to use the e-learning platform even though the e-learning process was mandatory during the COVID-19 period. Students had their handbooks at home, but those handbooks had not been designed for e-learning purposes. Studying the content of the uploaded teaching material revealed that teachers seldom uploaded educational material. Thus, the existing uploaded e-learning material did not cover all the topics of the courses. Lastly, we noticed that courses that were taught by teachers with the appropriate training were not sufficiently supported on the e-learning platform as would be expected.

Our findings constitute evidence that there is a lack of either skills or appropriate equipment for e-learning. Summarizing, we must point out that our findings are relevant to those of previous studies [25]. However, in our study, we focus on a specific period during which the use of ICT became mandatory. Furthermore, our findings indicate that even in that period, the implementation of ICT tools was not efficient without the appropriate motivation, skill acquisition, training and the fostering of a new culture oriented towards the adoption of ICT education. On the other hand, in contrast to the studies for the schools of primary education, those for higher education indicate that online education was more widely accepted by the teaching staff and students [26,27]. We believe that future research should explore using questionnaires to assess the beliefs of teachers regarding distance learning to help explain their responses to the mandatory implementation of e-learning. Hopefully, the implementation of e-learning tools could provide a kick-start for e-learning since it is now more familiar to both teachers and students. This study was based on content analysis and quantitative data descriptive analysis. This constituted a limitation since we believe that any further research needs to engage in an analytical discussion with the key players involved in primary education.

Author Contributions: Conceptualization, M.A.; Formal analysis, M.A.; Methodology, M.A. and C.M.; Project administration, M.A.; Supervision, C.M.; Writing—original draft, M.A.; Writing—review \& editing, M.A. All authors have read and agreed to the published version of the manuscript.

Funding: This research received no external funding.

Institutional Review Board Statement: Not applicable.

Informed Consent Statement: Not applicable.

Data Availability Statement: Data available upon request to the authors.

Acknowledgments: We would like to thank the Hellenic Ministry of Education and Religious Affairs for their contribution to this research by providing us with data on Greek primary schools.

Conflicts of Interest: The authors declare no conflict of interest. 


\section{References}

1. Skordoulis, M.; Alasonas, P.; Pekka-Economou, V. E-government services quality and citizens' satisfaction: A multi-criteria satisfaction analysis of TAXISnet information system in Greece. Int. J. Prod. Qual. Manag. 2017, 22, 82-100. [CrossRef]

2. Penalvo, F.J.G.; Lumbreras, C.C.; Palacios, R.C. Smart Learning. Appl. Sci. 2020, 10, 6964. [CrossRef]

3. Ilkyu, H.; Chonggun, K. The Research Trends and the Effectiveness of Smart Learning. Int. J. Distrib. Sens. Netw. 2014, 10, 2-9.

4. Ha, C.; Lee, S.Y. Elementary Teachers' Beliefs and Perspectives Related to Smart Learning in South Korea. Smart Learn. Environ. 2019, 6, 1-15. [CrossRef]

5. Barber, M.; Mourshed, M. How the World's Best-Performing School Systems Come out on Top; McKinsey and Company: London, UK, 2007.

6. Gobbo, C.; Girardi, M. Teachers' beliefs and integration of information and communications technology in Italian schools. J. Inf. Technol. Teach. Educ. 2001, 10, 63-85. [CrossRef]

7. Jimoyiannis, A.; Komis, V. Examining teachers' beliefs about ICT in education: Implications of a teacher preparation programme. Teach. Dev. 2007, 11, 149-173. [CrossRef]

8. Hinostroza, J.E.; Labbe, C.; Lopez, L. Technology Resources for Teacher Learning. Int. Encycl. Educ. 2010, 8, $222-227$.

9. Pelegrum, W.J.; Law, N. ICT in Education Around the World: Trends, Problems and Prospects; UNESCPO International Institute for Educational Planning: Paris, France, 2003.

10. Palfrey, J.; Gasser, U. Born Digital: Understanding the First Generation of Digital Natives; Basic Book: NewYork, NY, USA, 2008.

11. Naresh, R. Education after COVID-19 Crisis Based on ICT Tools. Purakala 2020, 31, 464-468.

12. Zarei, S.; Mohammadi, S. Challenges of Higher Education Related to e-learning in Developing Countries During COVID-19 Spread: A Review of the Perspectives of Students, Instructors, Policymakers, and ICT Experts. Environ. Sci. Pollut. Res. 2021, 1-7. [CrossRef]

13. McLoughlin, C.; Northcote, M.T. What Skills do I Need to Teach on Line? Researching Experienced Teacher Views of Essential Knowledge and Skills in Online Pedagogy as a Foundation for Designing Professional Development for Novice Teachers. Int. Study Assoc. Teach. Teach. 2017, 1, 1119-1129.

14. Glava, C.C.; Glava, A.E. Teaching Skills Training Trough e-Learning. Procedia Soc. Behav. Sci. 2010, 2, 1752-1756. [CrossRef]

15. Albrahim, F.A. Online teaching Skills and Competences. Turk. Line J. Educ. Technol. 2020, 19, 9-20.

16. Lee, J.L.; Hirumi, A. Analysis of Essential Skills and Knowledge for Teaching on Line. Annu. Proc. 2004, 1, 534-540.

17. ElearnigIndustry.com. Available online: https:// elearningindustry.com/surprising-skill-online-teachers-more-effective (accessed on 23 December 2016).

18. Tikhomirov, V.; Dneprovskaya, N.; Yankovskaya, E. Three Dimensions of Smart Education. Smart Educ. Smart e-Learning Smart Innov. Syst. Technol. 2015, 41, 47-56.

19. Kim, I.; Kuljis, J. Applying Content Analysis to Web-based Content. J. Comput. Inf. Technol. 2010, 18, 369-375. [CrossRef]

20. Bengtsson, M. How to Plan and Perform a Qualitative Study Using Content Analysis. Plus Open 2016, 2, 8-14. [CrossRef]

21. Hsieh, H.F.; Shannon, S. Three Approaches to Qualitative Content Analysis. Qual. Health Res. 2005, 15, 1277-1288. [CrossRef] [PubMed]

22. Jawale, V.K. Methods of sampling design in the legal research. Advantages and disadvantages. Online Int. Interdiscip. Res. J. 2012, 2, 183-190.

23. Tkachuk, V.; Yechkalo, Y.; Semerikov, S.; Kislova, M.; Hladyr, Y. Using Mobile ICT for Online Learning During COVID-19 Lockdown. In Information and Communication Technologies in Education, Research, and Industrial Applications, Proceedings of the ICTERI 2020, Kharkiv, Ukraine, 6-10 October 2020; Bollin, A., Ermolayev, V., Mayr, H.C., Nikitchenko, M., Spivakovsky, A., Tkachuk, M., Yakovyna, V., Zholtkevych, G., Eds.; Springer: Cham, Switzerland, 2021; pp. 46-67.

24. Aldama, C.; Pozo, J.I. How are ICT used in the classroom? A study of teachers' beliefs and uses. Electron. J. Res. Educ. Psychol. 2016, 14, 253-286. [CrossRef]

25. Amate, J.J.; De la Rosa, A.L.; Caceres, F.R.; Servano, A.V. The affection of COVID 19 in the Learning Process of Primary School Students. Asystematic Review. Educ. Sci. 2021, 11, 654. [CrossRef]

26. Troussas, C.; Krouska, A.; Sgouropoulou, C.; Voyatzis, I. Ensemble learning Using Fuzzy Weights to improve Learning Style Identification for Adopted Instuctionet Routines. Entropy 2020, 22, 735. [CrossRef] [PubMed]

27. Peimani, N.; Kamalipour, H. Online Education in the Post Covid-19 Era: Students' perception and Learning Experience. Educ. Sci. 2021, 11, 633. [CrossRef] 